\title{
Üniversite Öğrencilerinin Sosyal Görünüş Kaygıları İle Girişimcilik Düzeyleri Arasındaki İlişki
}

DOI: $10.26466 /$ opus.933385

\author{
* \\ Yeșim Avunduk* \\ * Dr., İstanbul Ayvansaray Üniversitesi, İktisadi İdari ve Soyal Bilimler Fakültesi, İstanbul/Türkiye \\ E-Posta: dryavunduk@gmail.com \\ ORCID: 0000-0001-6841-630X
}

Öz

Araştırmanın amacl, üniversite öğrencilerinin sosyal görünüş kaygılarn ile girişimcilik düzeyleri arasındaki ilişkinin belirlenmesidir. Araştırmanın örneklemini, İstanbul Ayvansaray Üniversitesi İktisadi, İdari ve Sosyal Bilimler Fakültesinde öğrenim gören ve amaçlı örneklemi yöntemi ile seçilen 87 erkek ve 148 kadın olmak üzere toplamda 235 kişi oluşturmuştur. Araştırmada veri toplama aracı olarak, Kişisel bilgi formunun yanı sıra; Hart ve ark. (2008) tarafından geliştirilen, Doğan (2010) tarafindan Türkçe'ye uyarlanan "Sosyal Görünüş Kaygısı Ölçeği" ile Yılmaz ve Sünbül (2009) tarafından geliştirilen "Üniversite Öğrencilerine Yönelik Girişimcilik Ölçeği" kullanılmıştır. Verilerin normal dağ̆llım göstermesinin anlaşılmasından sonra analizler, bağımsız t-testi, ANOVA ve Pearson Korelasyon testleri ile yapılmıştır. Analiz sonuçları; bireylerin cinsiyetlerine göre sosyal görünüş kaygısı ile girişimcilik düzeyleri arasında anlaml farklılık olduğu belirlenmiştir. Sinıf değişkenine göre ise, bireylerin girişimcilik düzeylerinde istatistiksel olarak farklhlı olduğu saptanmıştır. Katılımcıların refah durumlarına göre sosyal görünüş kaygıları ile girişimcilik düzeyleri arasında farklılık olduğu saptanmıştır. Son olarak, sosyal görünüş kaygısı ile girişimcilik düzeyleri arasında ilişki olmadığı saptanmıştır. Sonuç olarak, bireylerin sosyal görünüş kaygıları ile girişimcilik düzeylerinin sosyo-demografik özelliklere göre farklılı gösterdiği belirlenmiştir.

Anahtar Kelimeler: Üniversite Öğrencileri, Sosyal Görünüş Kaygısı, Girişimcilik. 


\title{
The Relationship between Social Appearance Anxieties and Entrepreneurship Levels of University Students
}

\begin{abstract}
The aim of the study is to determine the relationship between university students' social appearance anxiety and their entrepreneurship level. The sample of the study consisted of a total of 235 people, 87 males and 148 females, who were selected by the purposeful sampling method, studying at the Faculty of Economics, Administrative and Social Sciences of Istanbul Ayvansaray University. As a data collection tool in the research, besides the personal information form; Hart et al. (2008) and "Social Appearance Anxiety Scale" adapted to Turkish by Doğan (2010) and "Scale of University Students Entrepreneurship" developed by Yalmaz and Sünbül (2009) were used. After the normal distribution of the data was understood, the analyzes were performed by independent t-test, ANOVA and Pearson Correlation tests. Analysis results; It was determined that there is a significant difference between social appearance anxiety and entrepreneurship levels of individuals according to their gender. According to the class variable, it was determined that there is a statistically significant difference in the entrepreneurship levels of individuals. It was determined that there is a difference between social appearance concerns and entrepreneurship levels according to the welfare status of the participants. As a result, it was determined that individuals' social appearance concerns and entrepreneurship levels differ according to socio-demographic characteristics.
\end{abstract}

Keywords: University Students, Social Appearance Anxiety, Entrepreneurship. 


\section{Giriş}

Üniversite dönemi bireylerin sosyalleşme ortamlarının farklılaştığı ve artmaya başladığı dönemdir. Doğup büyüdüğü şehirden eğitim amacıyla farklı bir ildeki üniversiteye gitmesiyle birey aynı zamanda kültürel bir değişiklik ile karşı karşıya kalmaktadır. Aynı zamanda üniversitelerde öğrenciler eğitim hayatlarında ilk defa serbest kılık kıyafet ile öğrenim görmeye başlamaktadır. Özellikle bireyler dış görünüşlerine bu dönemde daha fazla dikkat etmektedir.

Sosyal görünüş bireylerin kendilerini bir tanıtım aracı olarak yansıttıkları konumdur. Birey kendilerinde beğendikleri ve güzel gördükleri özelliklerini dış görünüşünü kullanarak yansıtmaya çalışırlar. Bu yollardan biri iyi bir dış görünüşe sahip olmaktır. Hatta iyi bir dış görünüşe sahip olmak için bireyler estetik ameliyatlar olmakta ve spor branşıyla ilgilenmektedirler. Çünkü güzel ve beğenilen bir dış görünüş, bireyin kendine olan güvenini arttırmakta, psikolojik olarak sağlıklı olmasında etkili bir araçtır. Sosyal ilişkilerinde kendisini daha iyi ifade edebilmekte ve olumlu anlamda bireye etkisi olduğu düşünülmektedir (Gökdoğan, 1988; Grogan, 2016). Fiziksel görünüm bireyin çevresiyle kuracağ 1 iletişimi de etkilemektedir. İletişimde birey, boy, kilo ve kıyafetleriyle karşı tarafta bir etki bırakır. Aynı zamanda fiziksel görünüme göre iletişim şekli de değişebilmektedir (Gökcan, 2011). İş başvurularında kıyafete dikkat edilmesini örnek olarak gösterebiliriz. Mülakata çağırıldığı zaman genelde bireyler gömlek giymeyi tercih ederler. İşe verdikleri önemi daha mülakat aşamasında kıyafetleriyle göstermek isterler. Geçmişten günümüze fiziksek görünüm bireyin kendini toplum içinde var olma unsuru olarak görülmektedir. İnsanoğlunun fiziksel görünüşe verdiği bu değer kendisi için öncelik haline gelmiştir. Günümüzde ise gittikçe fiziksel görünüme verilen önem artmaya devam etmektedir (Kılıç ve Karakuş, 2006). Dış görünüşün bireyin kendisini nasıl algıladığı dışında, etrafındaki insanlar tarafından nasıl algılandıkları da önemlidir. Bireyin davranışları şekillenirken aynı zamanda etrafında olumlu izler bırakmak isterler. Bunu herkes başaramaz ve bazıları daha fazla kaygı duymaya başlarlar (Çepikkurt ve Coşkun, 2010). 
Son zamanlarda sosyal medya kanallarının artmasıyla birlikte sosyal mecralarda fiziksel görünüme önem verilmeye başlanmıştır. Günümüzde bireyler olması gerekenden fazla dış görünüşe ve başkalarının da fiziksel görünüşüne dikkat etmektedirler. Sosyal görünüş kaygısı, bireyin çevre tarafından beğenilip beğenilmediği hakkında yaşadığı kaygı durumudur. Sosyal anksiyetenin bir çeşididir. Bedensel görünüş sadece kilo ve boy gibi özellikler değildir. Aynı zamanda burun, kulak, çene yapısı gibi doğuştan gelen çok fazla özellikleri de içinde barındırmaktadır. Olumsuz beden imajı sosyal görünüş kaygısının oluşmasına sebep olmaktadır. Sosyal görünüş kaygısı yaşayan bireylerde olduğu gibi depresyon yaşayan bireylerde de kendileri hakkında olumsuz düşünceleri olabilmektedir. Ancak sosyal görünüş kaygısı olan bireyler kendilerini iyi hissettiğinde veya girdikleri ortamda mental olarak rahat davrandiklarında herhangi bir olumsuz düşünceye kapılmamaktadırlar (Doğan, 2009). Özellikle bu süreç ergenlik döneminde ortaya çıkmaya başlar. Birey için çevresi hakkında güzel ve çirkin kavramları oluşmaya başlamaktadır. Bedensel görünüşü hakkında bireye gelen geribildirim kaygılı duruma gelmesini sağlar. Olumlu geribildirimde mutlu olur. Ancak fiziksel görünüşü hakkında olumsuz yapılan bir geribildirim bireyin utanç duymasını sağlayabilir hatta sosyal ortamlardan uzaklaşmasına neden olmaktadır (Köknel, 2010). Herhangi bir bireyin dikkat noktası sosyal endişe haline gelebilmektedir. Farklı bireyler açısından olumlu bir değer taşımadığı gibi bireyin kendini değersiz hissederek olumsuz bir düşünceye kapılmasını sağlamaktadır (Beck, 2005). Bireyin kendi özellikleri hakkında olumsuz bir düşünce ortaya çıktığında endişe oluşmaya başlar. Olumsuz olduğu taktirde sosyal çevrede ötekileştirme durumuyla karşı karşıya kalmasına neden olmaktadır. Kendisini sosyal çevreden uzak tutmaya başlar, içine kapanık bir hale bürünebilir. Birey fiziksel özelliklerini tam anlamıla olumlu kabul edip özgüveni yüksek olduğu taktirde sosyal ortamlarda veya iş ortamında daha girişken bir tavır alabilmesini sağlamaktadır.

Girişimcilik kavramı son zamanlarda üzerine çok konuşulan bir konu haline gelmiş fakat ortak bir tanım bulunamamaktadır. Sosyoloji, ekonomi, psikoloji gibi çok farklı disipline uzanan bir konudur. Kişilerin var olan sınırlı kaynaklar ile fırsatlar ve imkanları kullanarak yenilikçi süreçler için kullanabilme yeteneğidir (Mitchell vd., 2002). Girişimcilik 
kavramıyla beraber öne çıkan diğer bir kavram girişimcidir. Richard Cantillon, girişimci olgusunu tarihte ilk kullanan kişidir. Cantillon, girişimciyi faaliyetlerini gelirlerini belirsiz, giderleri ise belirli koşullarda gösteren kişi olarak belirtmektedir. Girişimci sistem içinde büyük öneme sahip kişidir. Sistem içindeki arz-talep dengesini korumaktadır (Güney, 2008). Bir başka tanımda girişimcilik, pazarda var olan fırsatların risklerini de göz önüne alarak bu fırsatları ticari amaçla başlatarak devam ettirme süreci olarak tanımlanmaktadır (Gökerik, 2013). Aynı zamanda girişimcilik fırsatlardan fayda sağlama amacı da taşımaktadır. Girişimcilik ekonomik olarak ülkeye katkı da sağlamaktadır. Özellikle istihdam imkânlarının artması ve toplumun refah düzeyinin gelişmesine katkısı ile önemli bir değer olarak görülmektedir (Döm, 2006). Girişimci kişilerin diğer insanlardan farklı özellikleri vardır. Yenilik yapma isteği, iş fırsatlarını değerlendirme, risk alabilen ve liderlik özellikleri mevcuttur. Bu özelliklere sahip kişisel toplum tarafından olumlu karşılanarak ülke geneline yayılmasına neden olmaktadır. Aynı zamanda girişimci bireyler bağlı bulunduğu gruba ilham kaynağı olurlar (İlter, 2010). Girişimcilik bilgi çağına geçtikçe hızlanmaya başlamıştır. Var olan bilginin çoğaltılması için harcanan çaba olarak görülmektedir. Toplumda fark yaratmak ve hayalini gerçekleştirmek isteyen bireyler için bir kariyer fırsatı alanı haline gelmiştir (Ries, 2014). Girişimcilik ruhunun kazandırılması için üniversite ortamında alınan eğitim etkili olmaktadır. Birey bilgi sahibi oldukça, piyasada yer alan fırsatları ve tehditleri gördükçe hayal kurmaya başlar ve gerçekleştirmeye çalışır. Bu süreçte daha önce yapılan girişimcilik planlarını inceler ve başarılı olmuş kişilerin hayatlarını örnek almaya başlar. Özellikle üniversitede bireyin sosyal çevresinin genişlemesi ve kendini gerçekleştirme ortamının var olmasıyla girişimcilik kavramı olgunlaşmaya başlar. Bu bağlamda çalışmamızın amacı, üniversite öğrencilerinin sosyal görünüş kaygıları ile girişimcilik düzeyleri arasındaki ilişkiyi incelemektedir. 


\section{Yöntem}

\section{Araştırma Modeli}

$\mathrm{Bu}$ çalışma nicel bir çalışma olup, model olarak ilişkisel tarama modeli ile yürütülmüştür. İlişkisel modelde olgu ya da değişkenlerin ilişkisi, etkisi ve bunların dereceleri saptanmaya çalışılmaktadır (Kaya ve ark., 2012).

\section{Araştırma Grubu}

İstanbul Ayvansaray Üniversitesi İktisadi, İdari ve Sosyal Bilimler Fakültesinde öğrenim gören ve amaçlı örneklemi yöntemi ile seçilen 87 erkek (Ortyaş=22.59 \pm 3.15 ) ve 148 kadın (Ortyaş= 20.47 \pm 6.47 ) olmak üzere toplamda 235 kişi oluşturmuştur.

\section{Veri Toplama Araçları}

Kişisel Bilgi Formu: Araştırmaya katılan bireylerin cinsiyet, yaş, medeni durum, refah durumu, iş yeri çalışma şartları ve iş yerinde çalışma sürelerine ilişkin bilgileri tespit etmek amacıyla araştırmacı tarafından hazırlanan "Kişisel Bilgi Formu" kullanılmıştır.

Sosyal Görünüş Kaygısı Ölçeği: Bireylerin sosyal görünüş kaygılarını belirlemek amacıyla Hart ve ark., (2008) tarafından geliştirilen, Türkçe' ye Doğan (2010) tarafından uyarlanan "Sosyal Görünüş Kaygısı Ölçeği" Kullanılmıştır. Ölçek 16 madde ve tek boyuttan oluşmaktadır. Ölçek 5'li Likert olup (1=Hiç uygun değil; 5=Tamamen uygun) şeklinde cevaplanmaktadır. Güvenirlik kat sayısı 0.94 olarak tespit edilmiş olup, bu çalışmada ise iç tutarlılık kat sayısı ise, 0.90 Olarak belirlenmiştir

Girişimcilik Ölçeği: Araştırmaya katılan bireylerin girişimcilik düzeylerini belirlemek için Yılmaz ve Sünbül (2009) tarafından geliştirilen "Üniversite Öğrencilerine Yönelik Girişimcilik Ölçeği” kullanılmıştır. Ölçek 36 madde ve tek boyuttan oluşmaktadır. Ölçek 5'li Likert olup (1=Hiçbir Zaman; 5=Çok Sık) şeklinde cevaplanmaktadır. Güvenirlik kat sayısı 0.90 
olarak tespit edilmiş olup, bu çalışmada ise iç tutarlılık kat sayısı ise, 0.86 Olarak belirlenmiştir.

\section{Verilerin Analizi}

Analizler Spss 22 programı aracılı̆̆ 1 ile gerçekleştirilmiştir. Bireylerin demografik değişkenlerinin dağılımlarında frekans ve yüzde yöntemlerinden faydalanılmıştır. Verilerin normal dağılıp dağılmadını saptamak için Shapiro Wilks normallik testi kullanılmış ve test sonucunda verilerin normal dağılım gösterdiği belirlenmiştir. Daha sonra analizlerde $t$ testi, ANOVA ve Pearson Korelasyon testleri kullanılmıştır.

$\mathrm{Bu}$ araştırma İstanbul Ayvansaray Üniversitesi Akademik Araştırma ve Yayın Etiği Kurulu'nun 23.03.2021 tarih 2021/02 sayılı kurulunda görüşülmüş olup; araştırmanın etik ilkelere uygun olduğuna karar verilmiştir.

\section{Bulgular}

Tablo 1. Katılımcıların Kişisel Bilgilerinin Dă̆ılımları

\begin{tabular}{lll}
\hline Cinsiyet & $\mathbf{N}$ & $\%$ \\
\hline Kadın & 148 & 63,0 \\
Erkek & 87 & 37,0 \\
Toplam & $\mathbf{2 3 5}$ & $\mathbf{1 0 0}$ \\
Sinıf & & \\
1.Snnıf & 45 & 19,1 \\
2. Snnıf & 85 & 36,2 \\
3.Snnıf & 66 & 28,1 \\
4.Snnıf & 39 & 16,6 \\
Toplam & $\mathbf{2 3 5}$ & $\mathbf{1 0 0}$ \\
Refah Düzeyi & & \\
Kötü & 58 & 24,7 \\
Normal & 97 & 41,3 \\
Iyi & 80 & 34,0 \\
Toplam & $\mathbf{2 3 5}$ & $\mathbf{1 0 0}$ \\
\hline
\end{tabular}

Tablo 1'de araştırmaya katılan bireylerin kişisel bilgilerinin dağılımı verilmiştir. Analiz sonuçlarına göre; araştırmaya katılanların \%63,0'1 "Erkek", \%36,2'i "2.Sınıfta" öğrenim görürken, \%41,3'ünün ise refah durumu "Normal" olduğu belirlenmiştir. 
Tablo 2. Ölçek Puanlarının Dă̆ılımı

\begin{tabular}{|c|c|c|c|c|c|c|c|}
\hline Alt Boyutlar & & Madde Sayısı & $\mathbf{n}$ & Ort. & Ss. & Çar. & Bas. \\
\hline $\begin{array}{l}\text { Sosyal Görünüş } \\
\text { Kaygısı Ölçeği }\end{array}$ & $\begin{array}{l}\text { Sosyal Görünüş } \\
\text { Kaygisı }\end{array}$ & 16 & 235 & 2.49 & 0.98 & -.61 & 1.05 \\
\hline Girişimcilik Ölçeği & Girişimcilik & 36 & 235 & 3.20 & 1.40 & -.74 & 1.07 \\
\hline
\end{tabular}

Tablo 2'de çalışmaya katılan katılımcıların ölçek puanlarından aldıkları ortalama puanlar verilmiştir. Analiz sonuçlarına göre; sosyal görünüş kaygısı ölçeğinin ortalama puanı (2.49) olarak tespit edilirken; girişimcilik ölçeğinin ise, ortalama puanı (3.20) olduğu saptanmıştır.

Tablo 3. Cinsiyet Değişkenine Göre Ölçek Puanlarına İlişkin Bağımsız t-Testi Sonuçları

\begin{tabular}{llllll}
\hline & Cinsiyet & N & Ort. \pm Ss. & t & p \\
\hline \multirow{2}{*}{ Sosyal Görünüş Kaygısı } & Kadın & 148 & $2.79 \pm 0.82$ & \multirow{2}{*}{6.514} & \multirow{2}{*}{$\mathbf{0 0 0}^{*}$} \\
& Erkek & 87 & $1.99 \pm 1.02$ & & \\
\multirow{2}{*}{ Girişimcilik } & Kadın & 148 & $3.58 \pm 1.12$ & 5.834 & $\mathbf{. 0 0 0}^{*}$ \\
\hline
\end{tabular}

Tablo 3'de araştırmaya katılan bireylerin cinsiyetlerine göre ölçek puanlarına ilişkin bağımsız t-Testi sonuçları verilmiştir. Analiz sonuçlarına göre; bireylerin sosyal görünüş kaygıları arasında istatistiksel olarak anlamlı farklılık olduğu saptanmıştır $(\mathrm{p}<0.05)$. Kadınların ortalama puanları erkeklerden daha yüksektir. Benzer şekilde, bireylerin cinsiyetlerine göre girişimcilik düzeylerinde anlamlı farklılık belirlenmiştir $(p<0.05)$. Kadınların girişimcilik düzeyleri daha yüksek olduğu belirlenmiştir.

Tablo 4. Sınıf Değişkenine Göre Ölçek Puanlarına İlişkin ANOVA Analizi Sonuçları

\begin{tabular}{|c|c|c|c|c|c|c|}
\hline & Sinif & $\mathbf{N}$ & Ort. \pm Ss. & $\mathbf{F}$ & $\mathrm{p}$ & Fark \\
\hline \multirow{4}{*}{$\begin{array}{l}\text { Sosyal Görünüş } \\
\text { Kaygısı }\end{array}$} & 1.Sinif & 45 & $3.06 \pm 0.41$ & \multirow{4}{*}{4.598} & \multirow{4}{*}{.089} & \\
\hline & 2.Sinif & 85 & $3.04 \pm 0.38$ & & & \\
\hline & 3.Sinif & 66 & $2.89 \pm 1.07$ & & & \\
\hline & 4.Sinif & 39 & $2.84 \pm 0.58$ & & & \\
\hline \multirow{4}{*}{ Girişimcilik } & 1.Sinif & 45 & $4.02 \pm 0.47$ & \multirow{4}{*}{2.488} & \multirow{4}{*}{$.000^{*}$} & \\
\hline & 2.Sinif & 85 & $3.84 \pm 0.56$ & & & \multirow{3}{*}{$1-3$} \\
\hline & 3.Sinif & 66 & $3.67 \pm 0.86$ & & & \\
\hline & 4.Sinif & 39 & $3.89 \pm 0.41$ & & & \\
\hline
\end{tabular}

Tablo 4'de araştırmaya katılan bireylerin sınıflarına göre ölçek puanlarına ilişkin ANOVA analizi sonuçları verilmiştir. Analiz sonuçlarına göre; bireylerin sosyal görünüş kaygıları arasında istatistiksel olarak 
anlamlı farklılık olmadığ 1 tespit edilmiştir $(\mathrm{p}>0.05)$. Ancak, katılımcıların sınıf seviyelerine göre girişimcilik düzeyleri arasında anlamlı farklılaşma saptanmıştır $(\mathrm{p}<0.05)$.

Tablo 5. Refah Düzeyine Göre Ölçek Puanlarına İlişkin ANOVA Analizi Sonuçları

\begin{tabular}{|c|c|c|c|c|c|c|}
\hline & Refah Düzeyi & $\mathbf{N}$ & Ort. \pm Ss. & $\mathrm{f}$ & $\mathrm{p}$ & Fark \\
\hline & Kötü & 58 & $2.65 \pm 0.87$ & & & \\
\hline \multirow{2}{*}{ Sosyal Görünüş Kaygısı } & iNormal & 97 & $2.84 \pm 0.57$ & 2.046 & $.001^{*}$ & $1-3$ \\
\hline & İyi & 80 & $3.39 \pm 0.99$ & & & \\
\hline \multirow[b]{2}{*}{ Girişimcilik } & Kötü & 58 & $2.84 \pm 0.41$ & & & \\
\hline & Normal & 97 & $3.04 \pm 0.75$ & 3.894 & $.000^{*}$ & $1-3$ \\
\hline
\end{tabular}

Tablo 5'de araştırmaya katılan bireylerin refah durumlarına göre ölçek puanlarına ilişskin ANOVA analizi sonuçları verilmiştir. Analiz sonuçlarına göre; bireylerin sosyal görünüş kaygıları arasında istatistiksel olarak anlamlı farklılık olduğu saptanmıştır $(\mathrm{p}<0.05)$. Refah durumu iyi olan bireylerin ortalama puanları diğer bireylerden daha yüksektir. Benzer şekilde, bireylerin refah durumlarına göre girişimcilik düzeylerinde anlamlı farklılaşma vardır $(\mathrm{p}<0.05)$. Bu Bulgularda refah durumu iyi olan bireylerin ortalama puanları diğer bireylerden daha yüksek görülmektedir.

Tablo 6. Soyal Görünüş̧ Kaygısı ile Girişimcilik Arasındaki Korelasyon Analizi Sonuçları

\begin{tabular}{lll}
\hline & Sosyal Görünüş Kaygısı & Girişimcilik \\
\hline Sosyal Görünüş Kaygısı & 1 & 0.269 \\
Girişimcilik & 0.269 & 1 \\
\hline
\end{tabular}

Sosyal görünüş kaygısı ile girişimcilik arasındaki ilişkiyi belirlemek için yapılan Pearson Korelasyon analizi sonuçları tablo 6' da bulunmaktadır. Analiz bulgularına göre sosyal görünüş kaygısı ile girişimcilik arasında bir ilişki olmadığı belirlenmiştir ( $\mathrm{p}>0.05)$.

\section{Tartışma ve Sonuç}

Sosyal görünüş kaygısı, bireyin çevre tarafından fiziksel görünümün olumsuz olarak değerlendirilme düşüncesine sahip olma olarak tanımlanmaktadır. Beğenilme ihtiyacı hisseden ve özgüveni düşük olan 
bireylerde bu kaygının daha fazla görüldüğü söylenebilir. Girişimcilik ise, fırsatları değerlendirmek için riskleri göz önüne alarak harekete geçme eylemi olarak tanımlanmaktadır. Bu kapsamda araştırmanın amacı, üniversite öğrencilerinin sosyal görünüş kaygıları ile girişimcilik düzeyleri arasında ilişkisinin incelenmesidir. Araştırmada \% 63,0'1 (148) Kadın, \%37,0'1 (87) Erkek olmak üzere toplam 235 katılımcı yer almaktadır. Yapılan analiz sonuçları incelendiğinde Tablo 3'de katılımcıların cinsiyet değişkenine göre sosyal görünüş kaygısı ile girişimcilik düzeyleri arasında anlamlı fark olup olmadığını belirlemek için yapılan bağımsız T-tesi sonucuna göre anlamlı farklılıklar ortaya çıkmıştır. Literatürde daha önce yapılan çalışmalar incelendiğinde; Çetinkaya ve ark., (2019) tarafından yapılan "Lise Öğrencilerinin Sosyal Görünüş Kayg1 Düzeylerinin Bazı Değişkenlere Göre İncelenmesi" adlı çalışmada cinsiyet değişkenine göre sosyal görünüş kaygı düzeyleri arasında anlamlı ilişkiye rastlanmamıştır. Aynı zamanda İsmail (2018) tarafından yapılan "Mutluluğun Yordayıcısı Olarak Cinsel Benlik Şeması Ve Sosyal Görünüş Kaygısı" adlı çalışmada cinsiyete göre sosyal görünüş kaygısı arasında anlamlı farklılık ortaya çıkmamıştır. Ancak Toprak ve Saraç (2018) tarafından yapılan "Sporcuların Sosyal Görünüş Kaygısı Ve Kilofobı Düzeyleri Arasındaki İlişkinin İncelenmesi" adlı çalışmada cinsiyetlerine göre sosyal görünüş kaygısı arasında anlamlı farklılık ortaya çıkmıştır. Benzer şekilde Öcal ve ark., (2020) tarafından yapılan "Araştırma Görevlilerinde Ortoreksiya Nervoza ve Sosyal Görünüş Kaygısının Değerlendirilmesi" adlı çalışmada da cinsiyete göre sosyal görünüş kaygı düzeyleri arasında anlamlı farklılık ortaya çıkmıştır. Pan ve Akay (2015) tarafından yapılan "Eğitim Fakültesi Öğrencilerinin Girişimcilik Düzeylerinin Çeşitli Değişkenler Açısından İncelenmesi" adlı çalışmada cinsiyete göre girişimcilik düzeyleri arasında anlamlı farklılık tespit edilmemiştir. Benzer şekilde Taysı ve Canbaz (2014) tarafından yapılan çalışmada cinsiyete göre girişimcilik düzeyleri arasında anlamlı ilişki tespit edilmemiştir. Araştırma sonuçları, çalışma sonucumuzla farklılık göstermektedir.

Tablo 4'de katılımcıların sınıf değişkenine göre sosyal görünüş kaygıları ve girişimcilik düzeyleri arasında ilişki olup olmadığını belirlemek için yapılan analiz sonuçlarına göre; sınıf değişkeni ile sosyal görünüş kaygıları arasında anlamlı ilişki bulunamazken, girişimcilik 
düzeyleri ile sınıf değişkeni arasında ilişki anlamlı bulunmuştur. Literatürde yer alan çalışma sonuçları incelendiğinde, Tekeli (2017) tarafından yapılan “Beden Eğitimi Ve Spor Öğretmeni Adayları İle Diğer Öğretmen Adaylarının Sosyal Görünüş Kaygısı Ve Akademik Öz - Yeterlik Düzeylerinin Karşılaştırılması" adlı çalışmada sınıf değişkenine göre sosyal görünüş kaygısı arasında anlamlı farklılık tespit edilmemiştir. Ancak Telli ve Ünal (2016) tarafından yapılan “Üniversite Öğrencilerinin Sosyo-Demografik Özelliklerine Göre Sosyal Görünüş Kaygısı: Bir Alan Araştırması" adlı çalışmada sınıf değişkenine göre sosyal görünüş kaygısı arasında anlamlı ilişki tespit edilmiştir. Çalışma sonuçları ile literatürde yer alan sonuçlar benzerlik ve farklılık göstermektedir. Sınıf değişkeni ile girişim düzeyleri arasında literatürde yapılan çalışmalara bakıldığında, Pan ve Akay (2015) tarafından yapılan çalışma sonucunda anlamlı farklılık tespit edilmemiştir. Benzer şekilde Dolu ve ark., (2016) tarafından yapılan “Hemşirelik Öğrencilerinin Girişimcilik Düzeyleri İle Bazı İlişkili Faktörlerin Değerlendirilmesi" adlı çalışmada sınıf değişkenine göre girişimcilik düzeyleri arasında anlamlı ilişki tespit edilmemiştir. Araştırma sonucu, literatürde yer alan sonuçlarla farklılık göstermektedir.

Tablo 5'de katılımcıların refah durumu değişkenine göre sosyal görünüş kaygıları ve girişimcilik düzeyleri arasında ilişki olup olmadığını belirlemek için yapılan analiz sonuçlarına göre anlamlı farklılık tespit edilmiştir. Refah düzeyi “İyi” olan katılımcıların ortalama puanları diğer katılımcıların ortalama puanlarından yüksek bulunmuştur. Literatürde yer alan çalışma sonuçları incelendiğinde, Pehlivanoğlu ve Kayan (2019) tarafından yapılan “Türkiye' de Girişimcilik: Mevcut Durum Analizi ve Çözüm Önerileri" adlı çalışmada girişimcilik çalışmalarının artması, refah düzeyinin artmasına ve orta sınıfın güçlenmesine sebep olduğu sonucuna ulaşmışlardır. Refah seviyesi iyi olan özellikle rahat yaşayan insanların girişimcilik düzeylerinin daha yüksek olabileceği, risk almakta daha cesaretli olabileceği söylenebilir. İnsanların hayatta kalmaları için bir gruba ait olmaları gerekmektedir. Aktaş (2020) tarafından yapılan çalışmada grup tarafından dışlanmaya maruz kalan bireyin, grubun refah düzeyine bir katkı sağlamamasından kaynaklandığını belirtmektedir. 
Sonuç olarak; üniversite öğrencilerinin cinsiyet ve refah düzeyi değişkenlerine göre sosyal görünüş kaygıları ile girişimcilik düzeyleri arasında anlamlı farklılıklar ortaya çıkarken, sınıf değişkenine göre girişimcilik düzeyleri arasında anlamlı ilişki tespit edilmemiştir. Sonuçlara göre; üniversitelerde girişimcilik derslerinin arttırılmasının gerekmekte olduğu söylenebilir. Aynı zamanda sınıf farklılıkların ortadan kalkmasını sağlayabilir. Bireylerin, sosyal görünüş kaygılarından uzak kalmalarını sağlamak için iletişim becerilerini yükseltecek derslerin müfredatlara eklenmesi gerektiği söylenebilir. Böylelikle öğrencilerin fiziksel görünüşlerinden ötürü yaşayacakları kaygı kuvvetli iletişim ile çözüme kavuşabileceği sağlanabilir. 


\section{EXTENDED ABSTRACT}

\section{The Relationship between Social Appearance Anxieties and Entrepreneurship Levels of University Students \\ Yeşim Avunduk \\ Istanbul Ayvansaray University}

Social appearance is the position in which individuals project themselves as a promotional tool. Individuals try to reflect the features they like and consider beautiful in themselves by using their external appearance. One of these ways is to have a good appearance. Because a beautiful and admired appearance increases the self-confidence of the individual and is an effective tool for being psychologically healthy. He can express himself better in his social relations and is thought to have a positive effect on the individual (Gökdoğan, 1988; Grogan, 2016). Apart from how the individual perceives himself, how he is perceived by the people around him is also important. While the behavior of the individual is shaped, they also want to leave positive traces around them. Not everyone can do this and some start to worry more (Çepikkurt ve Coşkun, 2010). Anxiety begins to occur when a negative thought arises about the individual's own characteristics. If it is negative, it causes them to face marginalization in the social environment. He starts to distance himself from the social environment, and may become withdrawn. If the individual accepts his physical characteristics as fully positive and has high selfconfidence, it enables him to take a more assertive attitude in social or work environments.

The concept of entrepreneurship has become a hot topic recently, but a common definition cannot be found. It is a subject that extends to many different disciplines such as sociology, economics and psychology. It is the ability of people to use existing limited resources, opportunities and opportunities for innovative processes (Mitchell vd., 2002). In another definition, entrepreneurship is defined as the process of starting and 
continuing these opportunities for commercial purposes, taking into account the risks of existing opportunities in the market (Gökerik, 2013). Entrepreneurship has started to accelerate as it moves into the information age. It is seen as an effort to reproduce existing knowledge. It has become a career opportunity area for individuals who want to make a difference in society and realize their dreams (Ries, 2014). In order to gain the entrepreneurial spirit, the education taken in the university environment is effective. As the individual gains knowledge, as he sees the opportunities and threats in the market, he begins to dream and tries to realize it. In this process, he examines the entrepreneurship plans made before and starts to take the lives of successful people as an example. The concept of entrepreneurship begins to mature, especially in the university, with the expansion of the individual's social environment and the existence of an environment of self-realization. In this context, the aim of our study is to examine the relationship between university students' social appearance concerns and entrepreneurship levels.

Relational screening model was used in this study. In the relational survey model, a situation or event is described as it is, and the relationship, effect and degrees of the variables that cause this situation are determined (Kaya et al., 2012). A total of 235 people, 87 men and 148 women, were selected by purposive sampling method, studying at Istanbul Ayvansaray University Faculty of Economics, Administrative and Social Sciences. In addition to the personal information form, "Social Appearance Anxiety Scale" and "Entrepreneurship Scale" were used in the research. SPSS 22.00 package program was used to evaluate the data. Percentage and frequency methods were used to determine the distribution of personal information of the individuals participating in the research. Shapiro Wilks normality test was performed to determine whether the data showed normal distribution and after determining that the data showed normal distribution, independent t-test, ANOVA and Pearson Correlation analyzes were performed. This research was discussed at the Board of Academic Research and Publication Ethics Committee of Istanbul Ayvansaray University, dated 23.03.2021 and numbered 2021/02; It was decided that the research was in compliance with ethical principles. Social appearance anxiety is defined as having the thought of negatively evaluating physical appearance by the environment. It can be said that 
this anxiety is seen more in individuals who feel the need to be liked and have low self-confidence. Entrepreneurship, on the other hand, is defined as the act of taking action by considering the risks in order to evaluate the opportunities. In this context, the aim of the research is to examine the relationship between university students' social appearance concerns and their entrepreneurship levels.

As a result; While there were significant differences between university students' social appearance concerns and entrepreneurship levels according to gender and welfare level variables, no significant relationship was found between entrepreneurship levels according to class variable. According to the results; It can be said that there is a need to increase entrepreneurship courses in universities. At the same time, it can make class differences disappear. It can be said that courses that will increase communication skills should be added to the curriculum in order to ensure that individuals stay away from social appearance concerns. Thus, it can be ensured that students' anxiety due to their physical appearance can be resolved with strong communication.

\section{Kaynakça / References}

Aktaş, E. (2020). Ergenlerġn ebeveyne bağlanma stilleri ile sosyal görünüş kaygısı ve sosyal dışlanma düzeyleri arasındaki ilişkinin incelenmesi. (Yüksek Lisans Tezi). Necmettin Erbakan Üniversitesi, Eğitim Bilimleri Enstitüsü, Konya.

Beck, T. A. (2005). Bilişsel terapi ve duygusal bozukluklar. (A. Türkcan, Çev.), İstanbul: Litera Yayıncllı.

Çepikkurt, F. ve Coşkun, F. (2010). Üniversiteli dansçıların sosyal fizik kaygı ve beden imgesinden hoşnut olma düzeyleri. Pamukkale Spor Bilimleri Dergisi, 1, 17-24.

Çetinkaya, B., Gülaçtı, F. ve Çiftçi, Z. (2019). Lise öğrencilerinin sosyal görünüş kaygı düzeylerinin bazı değişkenlere göre incelenmesi. Opus Uluslararası Toplum Araştırmaları Dergisi, 10(17), 904-922.

Doğan, T. (2009). Bilişsel ve kendini değerlendirme süreçlerinin sosyal anksiyete açısından incelenmesi. (Yayımlanmamış doktora Tezi). Sakarya Üniversitesi, Sosyal Bilimler Enstitüsü, Sakarya.

Doğan, T. (2010). Sosyal Görünüş Kaygısı Ölçeği' nin Türkçeye uyarlaması: Geçerlik ve güvenilirlik çalışması. Hacettepe Üniversitesi Eğitim Fakültesi Dergisi, 39, 151-159. 
Dolu, İ.Ç., Temucin, E.D. ve Özkan, H.A. (2016). Hemşirelik öğrencilerinin girişimcilik düzeyleri ile bazı ilişkili faktörlerin değerlendirilmesi. Akademik Sosyal Araştırmalar Dergisi, 5(58), 28-34.

Döm. S. (2006). Girişimcilik ve küçük işletme yöneticiliği. Ankara: Detay Yayıncllık, s.30-31.

Gökcan K. (2011). Giyim kuşam ve fiziksel görünüm algısı. Erişim tarihi, 05 Ocak 2021, Erişim adresi, http://sosyalhizmetuzmani.org/ giyimkusam.html

Gökdoğan, F. (1988). Ortaöğretime devam eden ergenlerde beden imajindan hoşnut olma düzeyi. (Yayımlanmış Yüksek Lisans Tezi). Ankara Üniversitesi, Sosyal Bilimler Enstitüsü, Ankara.

Grogan, S. (2016). Body image: Understanding body dissatisfaction in men, women and children. UK:Taylor \& Francis

Güney, S. (2008). Girişimcilik - temel kavramlar ve bazı güncel konular. Ankara: Siyasal Kitabevi.

Hart, T. A., Flora, D. B., Palyo, S. A., Fresco, D. M., Holle, C. ve Heimberg, R. C. (2008). Development and examination of the social appearance anxiety scale. Assessment, 15, 48-59.

İlter, B. (2010). Girişimcilik sürecinde kadın girişimcilerin karşılaştıkları sorunların analizi: KADİGER örneği. Ankara: Adalet Yayınları.

İsmail, M. (2018). Mutluluğun yordayıcısı olarak cinsel benlik şeması ve sosyal görünüş kaygısı. (Yüksek Lisans Tezi). İstanbul Ticaret Üniversitesi, Sosyal Bilimler Enstitüsü, İstanbul.

Kaya, A., Balay,R. ve Göçen,A.(2012). Öğretmenlerin alternatif ölçme ve değerlendirme tekniklerine ilişkin bilme, uygulama ve eğitim ihtiyacı düzeyleri. International Journal of Human Sciences, 9(2), 13035134.

Kiliç, M. ve Karakuş, Ö. (2016). Üniversite öğrencilerinin sosyal görünüş kaygıları ile benlik saygıları ve yalnızlık düzeyleri arasındaki ilişkinin incelenmesi. Journal of Human Sciences, 13, 3837-3852.

Köknel, Ö. (2010). Kültür ve gençlik sorunları. Türkyılmaz, N.C. (Ed.) Çocuk ve ergen eğitiminde anne baba tutumları içinde (s.41-93). İstanbul: Timaş Yayınları.

Mehmet G. (2013). Şehir markalaşmasının girişimcilik eğilimi üzerine etkisi: Uşak İli örneği.Yayınlanmamış Yüksek Lisans Tezi. Selçuk Üniversitesi, Konya. 
Mitchell, R. K.,Nbusenitz, L., Lant, T., Mcdougall, P. P., Morse, E. A. ve Smith, J. B. (2002). Toward a theory of entrepreneurial cognition: Rethinking the people side of entrepreneurship research. Entrepreneurship Theory and Practice, 27(2), 93-104.

Öcal, E., Ünsal, A., Demirtaş, Z., Emiral, Ö.G. ve Arslantas, D. (2020). Araştırma Görevlilerinde ortoreksiya nervoza ve sosyal görünüş kaygısının değerlendirilmesi. Cumhuriyet Üniv. Să̆. Bil. Enst. Dergisi, 2(5), 49-59.

Pan, V.L. ve Akay, C. (2015). Eğitim Fakültesi öğrencilerinin girişimcilik düzeylerinin çeşitli değişkenler açısından incelenmesi. E-Journal of New World Sciences Academy, 10(2), 125-138.

Pehlivaoğlu, P. ve Kayan, K. (2019). Türkiye'de girişimcilik: Mevcut durum analizi ve çözüm önerileri. Kırklareli Üniversitesi İktisadi ve İdari Bilimler Fakültesi Dergisi, 8(1), 58-78.

Ries, E. (2014). Yalın yeni girişim. Çev. Ece Elgin. İstanbul: Özyeğin Üniversitesi Yayınları.

Taysı, K. ve Canbaz, S. (2014). Önlisans öğrencilerinin girişimcilik özelliklerini ve eğilimlerini belirlemeye yönelik bir araştırma. Electronic Journal of Vocational Colleges, 4(1), 59-67.

Tekeli, Ş.C. (2017). Beden eğitimi ve spor öğretmeni adayları ile diğger öğretmen adaylarının sosyal görünüş kaygısı ve akademik öz - yeterlik düzeylerinin karşılaştırılması. (Yüksek Lisans Tezi). Bartın Üniversitesi, Eğitim Bilimleri Enstitüsü, Bartın.

Toprak, N. ve Saraç, L. (2018). sporcuların sosyal görünüş kaygısı ve kilofobı düzeyleri arasındaki ilişkinin incelenmesi. SPORMETRE, 16(2), 111118.

Yılmaz, E. ve Sünbül, A. M. (2009). Üniversite öğrencilerine yönelik Girişimcilik Ölçeğinin geliştirilmesi. Selçuk Üniversitesi Sosyal Bilimler Enstitüsü Dergisi, 21, 196-203.

\section{Kaynakça Bilgisi / Citation Information}

Avunduk, Y. (2021). Üniversite öğrencilerinin sosyal görünüş kaygıları ile girişimcilik düzeyleri arasındaki ilişki. OPUS-Uluslararası Toplum Araştırmaları Dergisi, 18(43), 6377-6393. DOI: 10.26466/opus. 933385. 